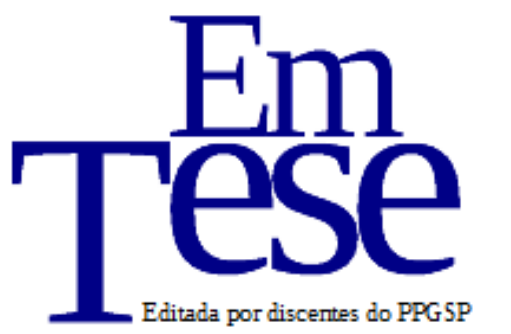

UFSC

PPG SP PROG RAMA DE

PÓS-GRADUAÇÃO EM

Sociologia

Política

V. 15, n. 2 p. 01, Julho, 2018.

DOI: http://dx.doi.org/10.5007/1806-5023.2018v15n2p198

\title{
O ponto de choque da moral: ação comunicativa, reconhecimento e redistribuição - Habermas, Honneth e Fraser ${ }^{1}$
}

\begin{abstract}
Aloizio Lima Barbosa ${ }^{2}$
Resumo: A moral se tornou, há muito, fruto de intensos debates na teoria social. Contemporaneamente, esses debates apresentam temas e abordagem que, cada vez mais, ganham importância. Uma parte crucial dessas questões contemporâneas vem do debate desenvolvido por Nancy Fraser e Axel Honneth sobre os conceitos de redistribuição e de reconhecimento. Partindo de posicionamentos diversos sobre o peso da moral dentro dos seus modelos teóricos, assim como o peso de reconhecimento e de redistribuição, ela e ele debatem acerca dos alicerces da teoria social pensando, em ambos os casos, em teorias abrangentes, que servem de importantes matrizes para uma sociologia crítica, na esteira da tradição de uma teoria crítica. O ponto em comum de ambos? A crítica a Habermas. Mapearei o pensamento habermasiano sobre a moral e, depois, as críticas de Honneth e Fraser ao autor para, no fim, tentar esboçar uma sociologia com base no dualismo de Frazer.
\end{abstract}

Palavras-chave: Moral. Teoria Crítica. Habermas. Redistribuição-Reconhecimento.

\section{The shock point of morality: communicative action, recognition and redistribution - Habermas, Honneth and Fraser}

\begin{abstract}
Morality has long been the fruit of intense debates in social theory. At the same time, these debates present themes and approaches that are becoming more and more important. A crucial part of these contemporary issues comes from the debate developed by Nancy Fraser and Axel Honneth on the concepts of redistribution and recognition. Starting from diverse positions on the weight of morality within its theoretical models, as well as the weight of recognition and redistribution, They debate about the foundations of social theory thinking, in both cases, in comprehensive theories, which serve as important Matrices for a critical sociology in the wake of the tradition of a critical theory. The common ground of both? The criticism of Habermas. I will map the Habermasian thinking on morals and then the criticisms of Honneth and Fraser to the author, in the end, to try to outline a sociology based on the dualism of Fraser.
\end{abstract}

Keywords: Moral. Critical Theory. Habermas. Redistribution-Recognition.

\footnotetext{
1 (c) EY Esta obra está licenciada com uma Licença Creative Commons Atribuição 4.0 Internacional.

${ }^{2}$ Mestre em Sociologia, Doutorando em Sociologia pela Universidade Federal de Pernambuco (UFPE) no Programa de Pós-graduação em Sociologia (PPGS). E-mail: aloizio.lima.barbosa @ hotmail.com
} 


\section{Introdução}

Quando se pensa os debates contemporâneos dentro das Ciências Sociais, os questionamentos sobre a moral ganham um espaço fundamental. No livro clássico de Boltanski e Thévenot, De la justification (1991), a moral é colocada nos quadros de uma encomia das grandezas e, com isso, pensada como processo amplo de justificação das ações para as pessoas. Dider Fassin (2013) oferece um esquema crítico sobre a antropologia moral e a maneira como os temas têm sido trabalhados na área. Existe, ainda, um grande esforço para recolocar a moral como elemento central dentro das investigações nas ciências sócias. Pensando na reflexão em teoria social, Frédéric Vanderberghe (2015) embarca em uma discussão que perpassa o argumento de que, com outros meios, a sociologia continua os antigos temas que eram de alçada da filosofia moral. De fato, levando em conta esses trabalhos e seus desdobramentos, a moral pode ser vista, hoje, como um tema inevitável para as ciências sociais, quiçá as ciências humanas.

Assim como a moral, as preocupações políticas se tornam evidentes, ou, pelo menos, alçadas ao nível analítico. Os valores que circundam as sociedades contemporâneos são resultados, no limite, de processos políticos históricos que reconfiguraram a forma como as pessoas se veem inseridas no mundo. Nesse sentido, do ponto de vista sociológico, as condições de possibilidade desses valores são questões cruciais para a compreensão das configurações sociais e de suas esperanças políticas. Assim, voltando aos alicerces da teoria social, o problema da ordem, da ação e da mudança (VANDERNBERGHE, 2012, p. 29), fazem-se presente como nunca.

Mas, então, o que se poderia entender como moral? De um modo relativamente genérico, moral e ética não têm uma diferença clara ${ }^{3}$, a moral representa o modo como um conjunto de valores aparece no espectro social e faz parte, de uma maneira ou de outra, dos aspectos que justificam determinadas ações para as pessoas. Como referência, a moral mostra sua dimensão sociológica mais imediata na sua ligação pela ação, de

\footnotetext{
${ }^{3}$ Se pensarmos em dimensões propriamente filosóficas, a ideia de moral, colocada como ética, o substantivo moral, é vista como uma conduta regulada pelos mores. Como adjetivo, moral é um objeto da reflexão ética, tema especialmente relacionado à avaliação das condutas valoráveis (ABBAGNAMO, 2007, p. 682).
} 
elementos de subjetivação. Nas ciências sociais, essa dimensão moral aparece tanto como objeto de análise - uma análise de como a sociedade é constituída de elementos morais - como um projeto a ser constituído, um projeto de sociedade (VANDERBERGHE, 2015, p. 65). E é por essa característica, principalmente quando se pensa em termos teóricos, que o lugar da moral dentro da reflexão nas ciências sociais é basilar.

Uma parte importante dessas questões contemporâneas vem do debate desenvolvido por Nancy Fraser e Axel Honneth sobre os conceitos de redistribuição e de reconhecimento. Partindo de posicionamentos diversos sobre o peso da moral dentro dos seus modelos teóricos, assim como o peso de reconhecimento e de redistribuição, ela e ele debatem acerca dos alicerces da teoria social pensando, em ambos os casos, em teorias abrangentes, que servem de importantes matrizes para uma sociologia crítica, na esteira da tradição de uma teoria crítica. Nesse sentido, a própria relação com o pensamento de Jürgen Habermas pode ser elencada como um aspecto interessante ao se abordar as questões envolvidas nesse debate.

Como essa pequena reflexão, no intuito de colocar Habermas, Fraser e Honneth para dialogar, farei uma pergunta para sintetizar o meu objetivo: qual o lugar do tema da moral nas críticas ao pensamento de Habermas, feitas por Fraser e Honneth, pensando suas implicações para a teoria social? Para que essa pergunta seja respondida, é preciso levar em consideração algumas consequências de suas teorias. Em um primeiro momento, desenvolverei o tema da ação comunicativa em Habermas, mostrando que a ideia de ética discursiva é inseparável de suas posições teóricas. Posteriormente mapearei, minimamente, o debate Fraser/Honneth a partir das críticas direcionadas a Habermas abordando as implicações morais, e a própria moral enquanto questão analítica, da díade redistribuição/reconhecimento. Na conclusão, tentarei trazer esse debate para o nível sociológico como uma sociologia da moral e uma sociologia política a partir de Nancy Fraser e alguns debates que essa posição implica. 


\section{Ação comunicativa: racionalidade comunicativa e a moral no mundo da vida}

Um bom modo de começar a argumentação acerca do pensamento de Habermas é ter a dimensão de sua relação com o Instituto de Pesquisas Sociais de Frankfurt, não em termos institucionais, mas em termos de ruptura com pressupostos importantes da geração que o antecedeu. Segundo Honneth (1999), três grandes linhas de pensamento faziam parte do quadro geral de pesquisas da assim chamada "Escola de Frankfurt" no pós-guerra: (I) Adorno e a racionalidade mimética como crítica ao pensamento conceitual; (II) Horkheimer e sua teologia negativa na qual a perda é o elemento constitutivo da experiência humana; (III) Marcuse e a recuperação da psicanálise, a natureza libidinal da revolução pensada dentro do quadro de necessidades humanas. Assim, essas três linhas de pensamento funcionariam como eixos hegemônicos de pesquisa que, em maior ou menos grau, faziam parte do Instituto.

A questão central dessas pesquisas, tendo em vista a continuação da tese de racionalização da cultura ocidental, é que existe um elemento totalizador nesse primado da racionalidade que é condicionante das questões subjetivas humanas. Com isso, o argumento se tornou quase um funcionalismo de matriz marxista (HONNETH, 1999, p. 537). O terreno de debate que Habermas se insere, em um primeiro momento, é o diálogo como esses argumentos e sua posterior superação ${ }^{4}$. A emergência de sua teoria é marcada pela pouca influência das tradições filosóficas anteriores e por uma certa autonomia no modo como o esquema conceitual foi pensando. $\mathrm{O}$ elemento de dominação, tão presente em um autor como Adorno, assume em Habermas um papel secundário, na medida em que ele incorpora uma reflexão de caráter sistêmico e, em determinado grau, integrativo. Nesse sentido, o que estava em jogo era, de fato, uma concepção diversa de sociedade.

O marco de compreensão da sociedade, em Habermas, é pensado a partir da articulação de uma filosofia hermenêutica com a teoria da linguagem presente em

\footnotetext{
${ }^{4}$ O ponto principal de Honneth quando ele escreve sobre a "Escola de Frankfurt" é mostrar como esses três referenciais teóricos tinham uma grande influência nos debates presentes em Habermas. Outro aspecto importante do argumento de Honneth é mostrar como existiam alguns autores, dentre os quais Walter Benjamin, que orbitavam entorno da teoria crítica sem necessariamente serem vinculados às pesquisas do Instituto. Isso é importante por mostrar como existia uma complexidade nessas formulações que também precisam ser recuperadas.
} 
Wittgenstein. Nesse sentido, a linguagem é percebida como mediadora e, ao mesmo tempo, constitutiva das experiências humanas, sejam elas individuais ou coletivas. Existe, com isso, uma compreensão de que, de uma forma ou de outra, a intersubjetividade está enrizada nas estruturas da língua. A compreensão graças a língua é o raciocínio fundamental para a reprodução da vida social e a consolidação da ordem (Ibid., p. 538) ${ }^{5}$.

Para pensar em linguagem e ordem, Habermas se vale do argumento da análise de sistemas presente em Parsons e mostra como essa dimensão é central para a compreensão das sociedades contemporâneas ${ }^{6}$. Mesmo assim, Habermas tem rupturas muito contundentes em relação ao funcionalismo e à tradição marxista. Essas rupturas deslocam o problema da moral, seja ela percebida como aspecto de coesão imediato, seja ela percebida como dimensão concreta do trabalho, para um aspecto simbólico, ou seja, para o espaço no qual, valores e linguagem fazem parte de um mesmo esquema. Habermas, com essa preocupação, rompe com uma concepção de história muito vinculada ao marxismo, ou seja, com uma concepção na qual a dimensão do trabalho é vista como única forma de mudança social, sendo essa crítica a primeira grande característica do seu projeto de síntese. Para tanto, ele mobiliza um sentido de história que, em consonância com a importância da linguagem para sua obra, aponta para a forma como ela é vista dentro do quadro de uma teoria da ação. Assim, a forma de vida humana é a história de compreensão pela língua, pelos símbolos (HONNETH, 1999, p. 539). Essa quebra, por assim dizer, é a primeira guinada de Habermas em direção a uma nova síntese.

\footnotetext{
${ }^{5}$ Como derivação dessa percepção, a questão da moral já aparece, indiretamente, como fruto de uma relação com a língua e com o modo como ela faz parte da experiência concreta das pessoas. Voltarei a esse ponto mais adiante. O Caráter de reprodução da vida social é visto como dinâmica, na medida em que a mudança também deriva do mundo da vida.

${ }^{6}$ Um problema que essa junção acarreta, apontado por Joas (1991), é que a dimensão hermenêutica, que poderia ser entendida a partir o conceito de mundo da vida mobilizado por Habermas, com a análise de sistema, que presa pela dimensão funcional dos componentes sistêmicos, é que ela leva a uma contradição. Existem duas concepções de ordem que são antagônicas (JOAS, 1991, p. 105) e Habermas as une como partes de um mesmo modelo analítico. Essa contradição terá desdobramentos importantes na localização da moral no pensamento de Habermas, boa parte desses desdobramentos estão relacionados com a relação entre mundo da vida e mundo do sistema. Ainda na argumentação de Joas, a ordem vista como um dado, fazendo parte da própria dinâmica dos sistemas, é diametralmente oposta ao entendimento da ordem como intersubjetividade calcada na linguagem, pensada em termos de mundo da vida. Assim, como mostrarei adiante, o peso da reprodução social ora cai no mundo da vida, ora cai no mundo do sistema.
} 
A concepção hegeliano-marxista de história somente abre espaço para mudanças em termos estruturais, apontando para mudanças na sociedade como um todo pela função do trabalho (JOAS; KNÖDLE, 2013, p. 222). Mas Habermas aponta para as ações individuais que carregam, assim, dimensões de aprendizado que são fundamentais, pois levam em conta a forma como as pessoas pensam e refletem sobre suas ações. Dessa forma, esse aprendizado só pode ser captado a partir de indivíduos concretos. O processo de aprendizagem individual, a maneira como as pessoas se apropriam de símbolos, é o foco inicial desse sentido de história pensado a partir das ações (Ibid., p. 223). No fundo, tentando superar o elemento quase determinista da história na tradição hegeliano-marxista, Habermas pensa na possibilidade de investigação do paralelismo entre uma dimensão Ontogênica (o processo de desenvolvimento do indivíduo da infância à fase adulta) e a dimensão filogênica (o desenvolvimento de processos sociais e culturais).

Entendendo esse ponto presente em Habermas, a mudança social passa a ser vista de duas formas. Primeiro, quando se pensa em mudanças geradas pelo trabalho, essas mudanças se concentram no mundo do sistema, ou seja, nas estruturas gerais que regem determinada sociedade. Quando se pensa em mudanças no mundo das interações, fala-se de mudanças no mundo da vida, o terreno simbólico a partir do qual o mundo do sistema pode surgir. Cada um desses "mundos" é regido por um tipo característico de racionalidade. O primeiro é moldado pela razão instrumental e o segundo é fundado pela razão comunicativa, ponto que voltarei mais adiante. Assim, a característica mais marcante da socialização humana é que a existência material - que se torna o mundo do sistema - depende de um acordo comunicativo fincado nas interações - interações essas que formam o mundo da vida (HONNETH, 1999, p. 540) ${ }^{7}$. A interação e os aspectos comunicativos garantem determinadas reciprocidades de valor e apontam para aspectos marcadamente simbólicos. Como os pragmatistas estadunidenses, Habermas liga as questões às interações simbolicamente mediadas.

\footnotetext{
${ }^{7}$ É interessante pensar como Habermas justifica as configurações do sistema a partir de acordos feitos no mundo da vida. Como questão contratualista em sentido amplo, ou seja, como formação de acordos comumente aceitos, esse argumento ganha mais força em Direito e Democracia (1997). No livro, a questão passa a ser a facticidade do direito, enquanto imerso no mundo dos sistemas, e sua validade, critério que só poderia ser dado pelo mundo da vida. A inferência feita por Habermas é que, de uma forma ou de outra, o Direito é fruto de instâncias democráticas que emergem no mundo da vida.
} 
A segunda característica é o abandono da noção de sujeito privilegiado, de um sujeito que seria condição necessária para os processos de transformação. $O$ alvo imediato de ruptura, e também de crítica, é a obra de Lukács e de sua influência no marxismo e nos movimentos sociais do pós-guerra. O principal ponto de ruptura para Habermas, é mostrar como a concepção de um sujeito privilegiado de transformação é fruto, ainda, da visão de história hegeliana, ou seja, a história como modelo lógico ${ }^{8}$. Essa mesma visão coloca os processos de transformação, de forma indireta, a cargo de um partido de vanguarda no modelo leninista (JOAS; KNÖDLE, 2013, p. 225-226). Uma coisa importante, levando em consideração essa crítica presente em Habermas, é que a noção de vanguarda, em Lukács, assume um aspecto mais geral, no sentido mesmo de ser colocada como motor da história, como motor dos processos de mudança 9 .

Dois pontos são importantes para o começo do delineamento do lugar da moral presente em Habermas. Quando ele separa os processos históricos em duas dimensões que se relacionam entre si, ele também aponta para o fato de que, em termos de interação entre as pessoas, a questão simbólica e da linguagem carrega características importantes que dizem respeito ao modo como, através da própria linguagem, os valores se tornam generalizados em determinado grupo. Os processos estruturais, o mundo do sistema, são frutos desse acordo permeado pelos símbolos. Ao recusar a ideia de um sujeito privilegiado para a transformação, Habermas também evidencia o caráter de interação entre as pessoas e mostra como, pelo aprendizado e pela própria língua, essa mudança ganha uma grande importância no nível mais micro, no qual todas as pessoas estão envolvidas diretamente, assim como o sentido moral da interação.

\footnotetext{
${ }^{8}$ Essa forma de pensar a relação lógica entre história e sujeito, tendo a própria ideia de história como um modelo lógico, está expressa em obras como História e Consciência de Classe (2012), na qual Lukács redefine a dialética marxista dentro da conceitualização da noção de vanguarda histórica, formulação essa presente em Lenin. Outro livro importante, mais voltado para o sujeito enquanto agente de transformação, é Para uma ontologia do ser social (2015). Uma das grandes viradas de Lukács é, justamente nessa obra, focar na vida cotidiano dos seres humanos, embora apontado apenas para como essa vida é derivada de condições estruturais.

${ }^{9}$ Istvan Meszáros (2013), esquematiza os fundamentos da obra de Lukács a partir da sua compreensão de dialética. Essa abordagem, de alguém que é lukacsiano, aponta alguns problemas centrais principalmente no interior do conceito de vanguarda, ou do vanguardismo histórico. De toda forma, a questão da mudança relacionada ao conceito de vanguarda permanece.
} 
A crítica de Habermas, sua posterior formalização em nível teórico, só se torna possível com um deslocamento importante na compreensão do que é racionalidade, do que é uma ação propriamente racional. Nesse sentido, o mundo da vida e o mundo do sistema apresentam características diferentes. O trabalho, relacionado ao segundo, e a interação, relacionada ao primeiro, são caracterizados por diferentes tipos de racionalidade ${ }^{10}$. Assim, o esquema de formação da racionalidade no Ocidente, inclusive o próprio processo de racionalização, ganham contornos mais complexos, apontando para desdobramentos diversos em vários sentidos. A interação, como elemento concreto da experiência das pessoas, assume uma forma independente de racionalidade ligada aos elementos da linguagem que estão presentes no mundo da vida. Dessa forma, o mundo da vida aponta para uma racionalidade comunicativa e o mundo do sistema é o lugar da racionalidade instrumental (HOENNETH, 1999, p. 540-541). Uma característica marcante dessa forma de compreensão da racionalidade é que, diretamente, a dimensão moral também é fruto dessa racionalidade comunicativa, pensada em termos de generalização para o grupo social no qual ela surgiu.

Existe, ainda, uma terceira característica da síntese habermasiana. Ela já foi explanada de forma indireta mas precisa ser, de fato, explicitada. Para dar poder analítico a sua obra, Habermas incorpora a teoria dos sistemas, mas especificamente, as formulações de Parsons sobre a evolução dos sistemas sociais humanos. Essa teoria do sistema, que também é objeto de crítica por parte do autor, tem a função de fundamentar, do ponto de vista lógico (teórico-comunicativo), uma teoria crítica da sociedade, ou seja, um projeto teórico mais geral que tenta dar conta dos processos de mudança na relação entre ação comunicativa e ação instrumental. Essa relação se torna um diagnóstico quando Habermas aponta para a forma como a ação comunicativa fundamenta a ação instrumental; a ação instrumental seria um desenvolvimento unilateral da razão comunicativa (Ibid., p. 542). Dessa forma, também como fruto de uma ação comunicativa, a própria moral é vista como constituída nas interações no mundo da vida e, portanto, tendo sua base mais central na linguagem.

\footnotetext{
${ }^{10} \mathrm{O}$ primeiro volume de Teoria do agir comunicativo (HABERMAS, 2012a) é dedicado ao estudo da racionalidade dentro da teoria social, mas especificamente e teoria social, e sociologia, alemã. A grande questão dessa investigação é mostrar que, nem todo tipo de racionalidade é uma racionalidade instrumental e, mais importante, racionalidade não significa somente reificação.
} 
Existe um esquema de leitura de Teoria do agir comunicativo (seus dois volumes). O livro pode ser divido em quatro partes fundamentais, cada uma dessas partes forma uma linha de argumentação que, à medida que o raciocínio avança, elas se complementam. A primeira parte envolve uma teoria da racionalidade, investigação e consideração de Habermas sobre as teorias que tratam da racionalidade e do processo de racionalização. Uma segunda parte pode ser destacada quando o autor investiga mais a fundo as teorias da ação que lidam com a noção de reflexividade e com um princípio de racionalidade que não seja visto apenas como razão instrumental. A terceira parte, que é um desdobramento das duas anteriores, é a investigação mais ampla sobre a ordem social. Nesse ponto, o autor lida mais diretamente com a teoria do sistema de Parsons e a refunda no diálogo constante com a noção de mundo da vida. Por fim, ele dá o seu diagnóstico das sociedades contemporâneas ao falar que, entre outras coisas, o mundo do sistema ganhou uma autonomia tal do mundo da vida que, como consequência, começou a invadir; sua tese passa a ser a colonização do mundo da vida pelo mundo do sistema (Habermas, 2012b, p. 298-305). É nessa tese, na forma como o mundo da vida passa a ser colonizado pelo mundo do sistema, que ocorre um deslocamento da moral em Habermas e ela, a partir da noção de crítica já fundada em Frankfurt, passa a entrar de forma mais direta no autor. A moral é fundada no mundo da vida, nos processos interativos e essa dimensão perdeu espaço para a racionalidade instrumental do mundo do sistema. A moral tem elementos de racionalidade muito claros, mas esses elementos dizem respeito aos acordos simbólicos realizados pela linguagem. Assim, quando se tem um princípio de racionalização como a razão instrumental, os acordos mudam de tom e passam a fazer parte da relação meios e fins ${ }^{11}$.

A definição de racionalidade é essencial para a compreensão da divisão, feita por Habermas, entre mundo da vida e mundo do sistema. Essa definição perpassa a ideia de que a racionalidade tem seu fundamento em uma racionalidade comunicativa; a ação racional, no mundo da vida, sempre pode apresentar seu potencial comunicativo, o

\footnotetext{
${ }^{11}$ A ação instrumental também representa, em determinado grau, uma moral. O utilitarismo clássico (MULGAN, 2012) fornece um bom exemplo dessa dimensão moral a partir da relação meios e fins na ação instrumental. Tendo o fim definido em termos de felicidade para o maior número de pessoas, boa parte da reflexão dos clássicos do utilitarismo gira entorno da fundamentação dos melhores meios para se atingir esse objetivo. Assim, quando Habermas aponta para um deslocamento moral no mundo do sistema, ele aponta par uma moral calcada na razão instrumental.
} 
conceito de reflexividade é muito importante para fazer essa passagem. A estrutura do argumento é contornar a tese de racionalização presente em Weber, dos desdobramentos da racionalização no Ocidente à estrutura lógica que forma os tipos ideais da ação (HABERMAS, 2012a, p. 305-320), com as formulações presentes em Mead - e a forma como a reflexividade está presente no conceito de self -, base central do conceito de mundo da vida, a partir de uma teoria da linguagem wittgensteiniana (HABERMAS, 2012b, p. 19-20). Nesse sentido, o conceito de atos de fala, presente na teoria de Wittgenstein, tem seu traço fundamental na forma como os indivíduos coordenam suas ações dentro de reivindicações de conhecimentos culturais que são acumulados e invariáveis, nos termos da organização do grupo. A mudança nesses conhecimentos se dá ao longo do tempo, pensando a passagem histórica das sociedades, a partir de um processo de racionalização cognitiva (Ibid.: 21-22). O mundo da vida, portanto, é a referência imediata por ter uma dimensão descentrada, fazendo com que as pessoas tenham suas ações no mundo dentro do aspecto do sucesso dos atos de fala. Existe, portanto, uma bifurcação da ação: a ação estratégica, referente à dimensão do sucesso, é diferente da ação instrumental (JOAS; KNÖDLE, 2013, p. 235; HONNETH, 1999, p. 542). As dimensões sistêmicas, portanto, têm seu substrato dentro dos atos de fala. A moral, como instância inerente ao processo de generalização dos conhecimentos, é o que torna possível, em determinado grau, a formação de processos sistêmicos.

A ação orientada pelo sucesso, que abstraída de sua referência do mundo da vida, dá as bases para o surgimento de modos de coordenação não-linguísticos, de modos que possam ser relacionados com dimensões comuns que não precisem, necessariamente, da interação. Os exemplos de Habermas para isso são o poder (institucionalidade) e o dinheiro (mercado). Consequentemente, os domínios da administração política e da produção econômica são esferas que passam a ser reguladas sem o acordo comunicativo, portanto sem a dimensão moral presente na linguagem. Isso tem a ver com a complexidade que os sistemas ganharam no desenvolvimento das sociedades ocidentais (HABERMAS, 2012b, p. 512-517). A grande questão presente na compreensão dessas esferas é que elas perdem seu elemento imediato de compreensão 
pela língua, caracterizando o processo de regulação da vida social e simbólica ${ }^{12}$. Essa é, em linhas gerais, a cisão histórica entre mundo da vida e mundo do sistema; também é a cisão entre dois tipos de moral que fazem parte do desenvolvimento das sociedades ocidentais. Aqui aparece a justificativa para o uso das teorias do sistema, mas especificamente a teoria parsoniana do sistema. Habermas vai justificar que os dois processos precisam ser investigados conjuntamente, o mundo da vida e o mundo do sistema, e que as esferas presentes no mundo do sistema só são acessíveis pela teoria do sistema (Ibid., p. 534-541). No percurso analítico, que o autor acaba tomando como distinção real, apontado por essas construções teóricas, funda-se uma teoria da modernidade coerente que tem como um dos objetivos mostrar os desdobramentos morais das sociedades ocidentais. E um desses desdobramentos é, justamente, a sua crítica.

A partir do momento em que o mundo do sistema, com sua racionalidade instrumental e uma moral baseada nos fins, interfere nos processos comunicativos do mundo da vida, tem-se o processo de colonização do mundo da vida. A teoria crítica da sociedade tem como função apontar esses processos e mostrar o potencial do agir comunicativo, no bojo da racionalidade comunicativa do mundo da vida e da própria reflexividade humana (Ibid., p. 689-716). Essa dimensão de colonização é a patologia derivada do grau de complexidade dos sistemas (HONNETH, 1999, p. 243). Habermas dá um salto: ele vai da análise do surgimento da moral no mundo da vida, para uma preocupação de que essa moral não se perca nos meandros da racionalidade instrumental.

A teoria crítica, com isso, deve explorar o que acontece no mundo da vida quando o agir comunicativo é controlado por meios instrumentais e sua função é substituída pela internalização do poder e do dinheiro, a tese da colonização do mundo da vida (Ibid., p. 672). Quando a passagem do mundo da vida para o mundo do sistema

\footnotetext{
${ }^{12}$ Norma, em Habermas, é a dimensão moral presente no mundo da vida. O sistema não faz referência às normas do acordo comunicativo, sendo aquele responsável pela reprodução a partir do grau de generalização. O exemplo do Direito é mais claro. A facticidade do Direito depende, necessariamente, da sua validade em relação às normas presentes no mundo da vida da comunidade política. Essas normas são fruto dos acordos comunicativos. Quando aplicado ao debate sobre a democracia, norma ganha outro significado, entendida como normatização. Aqui, Habermas fala dos processos de institucionalização das opiniões e das vontades, sempre pensando sua formação racional.
} 
gera sofrimento, a teoria precisa dispensar as formulações sobre valor, feitas por Marx, e se concentrar nos mecanismos de ação que tornaram esse sofrimento possível (Ibid., p. 673). Assim, existira uma necessidade de reflexão sobre os temas de estudo para que a justificativa de uma abordagem como essa possa dar conta dos aspectos levantados anteriormente. $\mathrm{O}$ modelo do dualismo deixa de ser uma estratégia analítica e passa a ser visto como real (Ibid., p. 674) ${ }^{13}$.

Tomando esse ponto como fundamental, Habermas aponta três programas de pesquisa que, embora tenham aspectos muito relevantes, apresentam limites por não lidarem diretamente com o dualismo mundo da vida/mundo do sistema de forma integrada. O primeiro deles é a linha da história social comparativista, depois a própria teoria do sistema e, por fim, os programas de teoria da ação. Depois de desenvolver cada um desses ponto, ele dirá que a teoria crítica da sociedade pode se assenhorar dessas três linhas de pesquisa lendo-as a partir do diagnóstico das patologias da modernidade (Ibid., p. 678). Com isso, pensado a retomada dos núcleos temáticos de Frankfurt, Habermas reaproxima as ciências sociais com as pesquisas amplas em filosofia tendo como pano de fundo o dualismo (Ibid., p. 680).

Mesmo tendo reformulado algumas vezes tanto o dualismo como o próprio conceito de crítica, o debate levantado por Habermas fez com que várias correntes das ciências sociais pensassem o lugar da crítica e o esforço teórico para operacionalizá-la. De toda forma, o ponto central dessa incursão no projeto da teoria crítica da sociedade é entender as formas de articulação entre mundo da vida e mundo sistema tendo em mente como um tipo de racionalidade, a comunicativa, deixou de ser o elemento de legitimação das ações e das esferas. Habermas tenta enfrentar seus fantasmas de Frankfurt apontando, mesmo que por um caminho completamente diferente deles, possibilidades de projetos críticos.

Habermas fornece um bom argumento de como as dimensões morais, que não são diretamente seu objeto, fazem parte de todo o processo de formação da teoria social e sociológica. O lugar da moral no mundo da vida, sua relação com a moral no mundo do sistema e forma como uma degradou a outra são as características mais centrais da

\footnotetext{
${ }^{13}$ Esse é o alvo de inúmeras críticas ao referencial habermasiano e ao modo como ele pensa desde a separação entre mundo da vida e sistema até o diagnóstico das patologias da modernidade. Não entrarei nos méritos e desenvolvimentos dessas críticas para não sair do foco.
} 
análise da moral presente em Habermas. Como preocupação, relacionado ao compromisso com a crítica, Habermas tenta mostrar como o agir comunicativo tem um fundamento racional não instrumental que é a base de uma ética discursiva, na qual os acordos de interação pela língua são fundamentais. A questão que fica, portanto, é que esse aspecto integrativo é resultado do próprio processo de formação da racionalidade comunicativa no Ocidente, e os conflitos são desvios desse mesmo processo.

\section{Redistribuição e reconhecimento: tensões e conflitos da moral comunicativa}

O repertório do referencial teórico de Habermas é vasto. O princípio do agir comunicativo como elemento característico de uma teoria da racionalização que encontra seu fundamento nas interações do mundo da vida é a questão mais básica para vários temas trabalhados pelo autor. O elemento central no qual Nancy Fraser e Axel Honneth concentraram suas críticas ao pensamento de Habermas, embora não seja o único, é o modo como o agir comunicativo, assim como a relação entre mundo da vida e mundo do sistema, repercute na teoria social habermasiana.

Os argumentos mais gerais de Habermas, sua filosofia política por exemplo, vistos sob essa ótica, são desdobramentos lógicos da teoria do agir comunicativo. Nesse sentido, os processos decisórios são vistos como ancorados no mundo da vida, no reino das interações entre as pessoas. Essas decisões passam para o nível sistêmico a partir da ideia de esfera pública, ideia essa que é uma mediação entre as duas instâncias (LUBENOW, 2010, p. 121). Fraser e Honneth, preocupados com as dificuldades que o pensamento de Habermas tem para pensar o tema do conflito, além das formas de opressão, partem de uma crítica comum e tomam caminhos diversos. A integração e o consenso como característica da racionalidade comunicativa, dão lugar ao conflito e as formas de dominação/opressão. No limite, a questão moral que nasce dos acordos mediados pela linguagem, desloca-se e entra no terreno das disputas; a moral em Fraser e Honneth, de início, é fruto dos conflitos.

O ponto em que convergem as críticas de Fraser e Honneth é, justamente, o dualismo na obra de Habermas, mais especificamente presente em Teoria do agir comunicativo. A divisão entre mundo da vida e mundo do sistema, como esferas 
separadas e com tipos de racionalidade característicos de cada uma delas, é vista, por ela e ele, como o maior problema do argumento presente no autor. Assim, embora tomem caminhos diferentes, essas críticas se centram na forma como as esferas se desenvolvem e atingem um grau de diferenciação que as tornam quase que independentes. De toda forma, o ponto de encontro com a teoria habermasiana é crucial para as reflexões de Fraser e Honneth (BRESSIANI, 2011, p. 338). O diagnóstico da formação de diferentes aspectos da racionalidade, a centralidade das interações e o lugar da normatividade, em Habermas, é, assim, o caminho para se pensar os conflitos em Fraser e Honneth.

O tratamento de Habermas ao tema da normatividade é um aspecto muito importante. A depender do lugar dos argumentos, a própria noção de normatividade ganha características diferentes. Como critério de legitimação dos acordos comunicativamente formados, a normatividade é vista como presente no mundo da vida - normatividade e moral. Quando relacionada ao desenvolvimento das sociedades ocidentais, a normatividade é vista como expressão da racionalidade instrumental presente no mundo do sistema; a normatividade, então, torna-se sinônimo de institucionalização. Dessa forma, como característica que vai definir que caminho Fraser e Honneth seguirão, a ambiguidade da análise da normatividade servirá de terreno básico para a crítica da separação entre mundo da vida e mundo do sistema. Essa compreensão é, entre outras coisas, a justificação que Habermas dá ao dualismo das sociedades contemporâneas; ele toma esse dualismo como real (HABERMAS, 2012b, p. 552-553). Dessa forma, em que consistiria, propriamente, as críticas de Honneth e Fraser?

Existe, a partir da forma como Habermas localiza sua tese da formação das sociedades Ocidentais, uma crítica fundamental na forma como ele localiza a normatividade e no modo como separa as esferas. Os desdobramentos dessa crítica é que são os temas das discordâncias entre Nancy Fraser e Axel Honneth. Os argumentos presentes em Honneth partem da ideia de que, como diagnóstico sobre a obra de Habermas, a tese da racionalidade e o processo de diferenciação que a caracterizou foi, aos poucos, tornando-se uma distinção empírica entre duas esferas independentes uma da outra. Ele argumenta que, como deslocamento do argumento de Habermas, as lutas pela normatização dão lugar ao conflito e a pressão pela adaptação exercida pelas 
organizações sociais e as ações organizadas comunicativamente, em termos de uma moral negociada via interação (BRESSIANI, 2011, p. 339). Como o abandono do processo inicial de luta presente em sua análise, Honneth afirma que Habermas criou duas ficções teóricas: (I) o mundo do sistema como sendo uma esfera não-linguística e totalmente diferenciada do mundo da vida e, como consequência, (II) um mundo da vida pensando como isento de qualquer tipo de assimetria ou que seus acordos linguísticos não envolveriam, a princípio, relações de poder assimétricas (Ibid.: 340). Honneth destaca a forma como o desenvolvimento da moral não é pensado para as decisões no mundo sistema e como, dentro da racionalização da normatividade, Habermas pensa o poder ${ }^{14}$ e o trabalho dentro de elementos morais que tem como base a relação meios e fins. A questão, portanto, é mostrar como cada uma dessas esferas dependem de elementos intersubjetivos específicos e que, como fruto das interações, esses elementos estão permeados por dimensões morais. Tanto a dimensão do trabalho como o poder devem ser pensados em consonância com comunicação e não apenas em termos instrumentais.

Para pensar as formas que essas dinâmicas devem ser analisadas em paralelo juntas, Honneth adota o seu monismo via a noção ampla de reconhecimento (HONNETH, 2003a). Para fundamentar seu monismo, Honneth entende que falar em reconhecimento não é o mesmo que falar em reconhecimento cultural. A noção aponta para dimensão polítcas e morais que perpassam todas as instâncias da sociedade. Reconhecimento, portanto, diz respeito às expectativas morais dos sujeitos mediante o processo de interação com outras pessoas. Nesse sentido, a noção de reconhecimento manifesta-se em três esferas: o amor, o direito e a solidariedade (Honneth, 2003a, p. 155-158). Por serem localizadas no plano moral, as interações dependem dessas esferas de reconhecimento para se consolidarem. Quando alguma dessas esferas é rompida, a interação acarreta os sentimentos de desrespeito e injustiça, levando o conflito a atingir outro patamar, um patamar de luta por reconhecimento (Ibid., p. 214-215) ${ }^{15}$.

\footnotetext{
${ }^{14} \mathrm{Se}$, concordando com Honneth, pensarmos em uma questão mais elementar, a própria forma como Habermas liga poder e institucionalização - burocracia estatal - é um pouco redutora. O poder ligado apenas às instituições não pode perceber, por exemplo, as assimetrias pressentes na própria formação dos acordos comunicativos presentes nos momentos de interação.

${ }^{15}$ Ao colocar as interações na dimensão das expectativas morais, Honneth pode ser lido em paralelo com Boltanski e Thévenot (1991) que, com a ideia de justificação para as ações, lançam a moral em patamares
} 
O modo como o conjunto das injustiças é percebido pela noção ampla de reconhecimento visa, entre outras coisas, uma localização dessas mesmas injustiças sociais a partir de um ponto de vista moral e, com isso, sua justificação. Honneth, assim, busca uma identificação dessas lutas no plano real com um comprometimento direto com a emancipação a partir das relações recíprocas de reconhecimento (HONNETH, 2003 b, p. 155-157) ${ }^{16}$. Como a interação é vista permeada pelo conflito, a justiça e o desrespeito tornam-se categorias amplas que configuram graus específicos do não atendimento das demandas de reconhecimento dessa mesma interação.

A característica mais marcante para se pensar essa categoria ampla de reconhecimento, seguindo o argumento de Honneth, é que tanto as lutas materiais, que buscam redistribuição de recursos, como as lutas por reconhecimento cultural estão inseridas em seu escopo. Por ser uma categoria moral, que tem um horizonte ético específico - a realização do reconhecimento recíproco - o sentido de justiça é o que mobiliza o reconhecimento de todas essas lutas. Contra o dualismo habermasiano, Honneth mostra um monismo fundado na categoria de reconhecimento que tenta mostrar as várias dimensões das injustiças e formas de dominação dentro de um quadro de interação moral que, mesmo presente em Habermas, fica restrito às interações sistêmicas. A tese de colonização do mundo da vida, presente em Habermas, perde força na medida em que as racionalidades se entremeiam em conflitos morais e a normatividade, que em si é uma disputa, torna-se derivada desses mesmos conflitos, no sentido de ser posta como um horizonte no qual demandas por reconhecimento serão, ou não, atingidas e ampliadas. A moral em Honneth, também fundada na interação, ganha contornos diversos de Habermas, fazendo referência a todas as experiências humanas, experiências essas de reconhecimento.

A forma que Fraser articula o pensamento de Habermas é diferente da apresentada por Honneth. Primeiramente, pode-se dizer que a crítica dirigida a tese de

de justificação das pessoas, ganhando contornos de mobilização. Quando a expectativa não é cumprida, a justificação precisa ser buscada em outro tipo de referência moral. Em Honneth, esse passo seguinte é o sentimento de injustiça e a luta por reconhecimento. Em Boltanski e Thévenot a questão se torna a crise do modelo de justificação.

${ }^{16}$ Já inserido no debate com Fraser, Honneth tenta mostrar que o monismo dotado por ele faz referência aos modos como a sociedade capitalista produz suas injustiças a partir da não consolidação das expectativas de reconhecimento. Dentro do debate entre ela e ele, esse diagnóstico é importante. Voltarei a polêmica mais a frente. 
colonização do mundo da vida é uma crítica com a qual ela concorda, no sentido de entender que a extensão da racionalidade do sistema para o nível das interações humanas não é o centro das patologias sociais presentes nas sociedades contemporâneas. Sua discordância com Honneth, em seguida, parte do momento em que, como Habermas, ela admite a diferenciação da sociedade entre duas esferas que, embora interligadas e interdependentes, têm suas especificidades que precisam ser levadas em consideração (BRESSIANI, 2011, p. 340) Fraser, com isso, admite um dualismo que, analiticamente, é operacionalizado pelos conceitos de economia e cultura $^{17}$. O que ela quer apontar é que, como relacionada à noção de lucro, a dimensão econômica precisa de uma certa autonomia na sua compreensão para que essas questões, lucro e estrutura econômica, possam ser melhor entendidas.

Fraser ataca o dualismo presente em Habermas a partir da forma como esse mesmo dualismo repercute na teoria social do autor, principalmente na rígida separação entre o mundo do sistema e o mundo da vida. O dualismo habermasiano, na visão da autora, pressupõe que, de uma forma ou de outra, as duas esferas sociais tenham seus espaços muito bem definidos. Nesse sentido, Fraser afirma que o dualismo de Habermas é substantivo, pois ele colocaria essas esferas como elementos reais de diferenciação na formação das sociedades ocidentais. Já ela teria uma dualismo analítico, que tem como objetivo mais básico diagnóstico de características específicas da economia e da cultura (Ibid., p. 341) ${ }^{18}$. Essa crítica leva a autora a assumir uma espécie de dualismo perspectivo que mantém a distinção entre sistema (economia) e mundo da vida (cultura e interação) mas os dota de uma flexibilidade, ou seja, tomando as dimensões como sendo mutualmente influenciáveis (FRASER, 2006, p. 234). A questão, portanto, é mostrar como dificilmente o dualismo presente em Habermas dá conta do conjunto das injustiças presentes no mundo contemporâneo. Fraser vai mostrar isso a partir da noção

\footnotetext{
${ }^{17}$ Em Escalias de Justicia (2012), Fraser argumenta acerca de uma terceira esfera que permeia as sociedades contemporâneas. Ela aponta para como a noção de representação é importante como dimensão política relativamente autônoma. Com isso, a autora incorpora em seu pensamento uma reflexão mais ampla sobre democracia e sobre como o político se relaciona com o mundo globalizado. Como referente às suas críticas direcionadas ao pensamento de Habermas e Honneth, tratarei aqui com seu dualismo. ${ }^{18}$ Fraser (1985) usa da categoria de gênero para fazer um grande mapeamento da teoria social e, em Habermas, tentar mediar o dualismo presente no autor. Esse ponto é interessante para mostrar que, antes dos debates diretos com Honneth, ela já atentava para a não possibilidade de esgotamento das injustiças a partir da categoria de reconhecimento.
} 
de gênero que, tanto no sistema como no mundo da vida, condiciona determinadas injustiças que não têm a ver com diferentes tipos de racionalidade (FRASER, 1985, p. 98-99).

Se as críticas de Fraser com relação às patologias sociais se aproximam das de Honneth, elas se diferenciam no momento em que, com uma nítida preocupação política, Fraser aponta que a relação com os movimentos sociais é fundamental. Os movimentos sociais, para a autora, são as fontes mais importantes para se apontar um determinado processo de exclusão (FRASER, 1985). Esse posicionamento se justifica tendo em mente o próprio nexo lógico presente na autora que é o da possibilidade de paridade na participação. Envolvendo uma teoria da justiça e tomando o problema moral como um problema político, Fraser vê nos movimentos sociais uma função muito importante na denúncia dos impedimentos a essa paridade na participação. A relação da moral, portanto, é com o conceito de justiça e sua chance de realização. Antes de entrar nesse meandro, é necessário desenvolver um pouco mais a crítica da autora direcionada a Habermas.

Fraser aponta um outro limite fundamental ao analisar a obra de Habermas. O dualismo de Habermas não consegue captar um conjunto grande de atividades que não entram na separação sistema e mundo da vida. A criação dos filhos é algo que, por exemplo, demanda uma mobilização no plano econômico, afinal a alimentação das crianças é algo fundamental, ao mesmo tempo que o elemento cultural/moral assume uma certa centralidade (Ibid.: 100-104). Quando Habermas pensa em dois tipos de integração - a sistêmica ligada a racionalidade instrumental e a cultural ligada ao mundo da vida - ele as coloca como tendo funções separadas. Fraser mostra que a reprodução material e as normas socialmente aceitas sempre estão entrelaçadas (Ibid., p. 120-121). Assim, no lugar de separar duas formas de integração que se ligam a dois mecanismos de racionalidade, a autora mostra que esses dois modos de integração são, na verdade, dois aspectos da sociedade que precisam ser tratados como interdependentes.

Essa compreensão das esferas do sistema e do mundo da vida repercute diretamente na maneira como Fraser articula não só sua crítica a Habermas, mas também na forma como ela argumenta sobre a impossibilidade da compreensão das 
injustiças sociais apenas por uma categoria, e isso a diferencia, mais uma vez, de Honneth. Como ele, Fraser também compartilha da crítica de que Habermas usa o conceito de poder de uma forma um tanto quanto restrita, ao associá-lo apenas a administração burocrática. Um outro ponto em comum é, como dito anteriormente, o diagnóstico das patologias e a maneira como Habermas reduz essas patologias à tese de colonização do mundo da vida pelo sistema. Os mecanismos de dominação, para ela, devem ser pensados também em ambientes de interação e, com isso, devem ser pensados com características próprias dentro das ações comunicativamente guiadas, para que não tenha uma compreensão limitada das patologias sociais e das formas de dominação. A tese de colonização do mundo da vida, assim, é muito limitada (BRESSIANI, 2011, p. 343). Tanto o capitalismo depende de formas de interação concreta entre as pessoas, em nível sistêmico, quanto o mundo da vida tem características do sistema que são constitutivas do próprio mundo da vida.

Dessa forma, o dualismo presente em Fraser perpassa um dualismo no diagnóstico dos diferentes tipos de normas presentes nas sociedades contemporâneas. Mesmo admitindo a inter-relação entre as esferas, a autora mantém o dualismo, no sentido de tentar dar conta de elementos específicos presentes em cada esfera. A economia, como esfera específica, tem tipos de injustiças relacionadas ao lucro que precisam ser apontadas como tal. $\mathrm{O}$ ideal de justiça, portanto, depende fundamentalmente da compreensão a partir do dualismo. A tese de colonização do mundo da vida pelo sistema, nesse sentido, não é suficiente para uma teoria crítica.

E é justamente no ataque à ideia de colonização do mundo da vida que Fraser discorda da possibilidade de compreensão apenas pela noção ampla de reconhecimento, ela ataca o monismo de Honneth e defende o seu dualismo. Mas, em que consiste, com isso, o dualismo do esquema teórico de Fraser?

\section{O dualismo de Fraser e a justiça como teoria da moral}

Habermas defende um dualismo (empírico e substantivo) que separa duas esferas sociais e coloca a moral como fruto de uma delas, o mundo da vida. Honneth critica essa separação e pensa na moral como sendo a mediadora de todas as relações 
sociais a partir da categoria de reconhecimento. Nancy Fraser, rejeitando o dualismo habermasiano e monismo de Honneth, coloca a possibilidade de um dualismo analítico a partir do debate sobre justiça. De um ponto de vista mais normativo, esse debate leva em conta os impedimentos e as possibilidades de paridade na participação.

Refletindo sobre o estatuto das lutas políticas no mundo contemporâneo, a autora argumenta que a centralidade do reconhecimento cultural retirou a importância, em termos de mobilização política, da esfera da redistribuição de recursos materiais. $\mathrm{O}$ fim do socialismo real despolitizou a economia e trouxe à tona a politização de questões étnicas e raciais (FRASER, 2006: 231). Nesse sentido, as lutas por reconhecimento se tornaram a dimensão paradigmática do fazer político no mundo. A dominação cultural passou, segundo ela, a ser a injustiça fundamental. Fraser constrói sua resposta partindo da argumentação de que é impossível remeter a totalidade das injustiças a partir de uma única categoria e que, de uma forma ou de outra, existem dimensões específicas que só podem ser pensadas a partir de suas características específicas. As sociedades contemporâneas estão perpassadas por dois mecanismos de injustiça que apontam para duas soluções diferentes: injustiças econômicas e culturais demandam redistribuição e reconhecimento (Ibid., p. 232-233) ${ }^{19}$. Essa divisão guarda consigo a característica de tratar as duas esferas como interdependentes e, com isso, mostra como demandas de uma podem ser demandas da outra. Cada uma dessas esferas exerce uma influência sobre a outra que, mesmos separadas analiticamente, não podem ser tomadas como independentes.

As injustiças decorrentes de uma determinada situação de exploração econômica precisam, como tal, de uma percepção dentro do quadro de relações da economia e com o lucro. Quando a questão é propriamente no nível da interação, é preciso apontar para a injustiça específica que essa relação acarreta. Dadas essas especificidades, Fraser argumenta que existem inter-relações morais na economia e inter-relações econômicas no nível da interação que os tornam interdependentes (FRASER, 2003: 13-14). A questão central, portanto, que fundamenta o dualismo em Fraser é sua relação com a justiça, ou seja, com a paridade na participação. Nesse sentido, o ponto normativamente

\footnotetext{
${ }^{19}$ Como dito anteriormente, Fraser vai lançar mão de uma outra esfera, da representação, para acrescentar ao seu modelo que, assim, deixa de ser dual. No artigo em questão, que abre a polêmica com Honneth, seu esquema ainda é da divisão de duas categorias.
} 
guiado da autora, que localiza a moral dentro da relação entre as esferas sociais, é a realização, ou não, da justiça. As injustiças apontadas têm dimensões muito complexas para serem pensadas como completamente separadas, ao mesmo tempo, suas características específicas só são observáveis se se leva em conta o que define cada esfera. É por isso que a autora reivindica uma teoria da justiça dual, que ponte para as inter-relações e, ao mesmo tempo, elenque as especificidades.

$* * *$

Na relação com o pensamento de Habermas, a partir do lugar da moral, Honneth e Fraser desenvolvem críticas muito importantes, cada qual apontando para uma saída diferente. Honneth, via reconhecimento, aponta para o modo como Habermas negligenciou os mecanismos de conflito em um esquema muito rígido de separação entre mundo do sistema e mundo da vida, separação vista por Honneth com uma ficção. Fraser compartilha de parte dessa crítica, mas, mantendo, em algum grau, o dualismo de Habermas, argumenta em favor de um dualismo que dê conta de dimensões da justiça que efetivem a paridade de participação.

O que fica relativamente claro nessas dimensões - recuperando a pergunta inicial do trabalho - é que a moral em Honneth carrega elementos relacionados às formas de interação e esses elementos implicam, também, o conflito que está subjacente no contato das ações comunicativas. Em Fraser a moral, diferente da questão nomartivainstitucional, só pode ser articulada com uma preocupação teórica voltada para a dimensão da justiça e, assim, efetivar a tarefa crítica fincada na paridade de participação. Em termo sociológicos, o dualismo de Fraser parece ter uma dimensão analítica mais potente, no sentido de separar as esferas e, ao mesmo tempo, elencar pontos em que elas estejam mutualmente comprometidas. A preocupação com a justiça coloca uma possível teoria da moral presente em Fraser, em acordo com uma série de desafios que a teoria sociológica precisa enfrentar. Além disso, quando incorporada ao problema da participação, tem elementos fundamentais para a investigação da democracia, para além da institucionalidade, que a coloca como referência fundamental para uma sociologia política. 


\section{Referências}

ABBAGNANO, Nicola. Dicionário de Filosofia. São Paulo: Martins Fontes, 2007.

BOLTANSKI, Luc; THÉVENOT, Laurent. De la justification: les économies de la grandeur. Paris: Gallimard, 1991.

BRESSIANI, Nathalie. Redistribuição e reconhecimento - Nancy Fraser entre Jürgen Habermas e Axel Honneth. Caderno CRH. Salvador, v. 24, n. 62, p. 331-353, Maio/Ago. 2011.

FASSIN, Didier. Moral Anthropology: a critial reder. Routledge, 2013.

FRASER, Nancy. What's critical about critical thoery? The case of Habermas and gender. New German Critique. Duke University press, n. 35, p. 97-131, 1985.

Social justice in the age of identity politics: redistribution, recognition and participation. In: FRASER, Nancy; HONNETH, Axel. Recognition or Redistribution? Londres: Verso, 2003b.

Da redistribuição ao reconhecimento? Dilema da justiça numa era "póssocialista”. Cadernos de campo. São Paulo, n. 14/15, p. 1-382, 2006.

Escalas de justicia. Herder Editorial, 2012.

HABERMAS, Jürgen. Direito e democracia: entre a facticidade e a validade, volume 1. Rio de Janeiro: Tempo Brasileiro, 1997.

Teoria do agir comunicativo: Volume I - racionalidade da ação e racionalidade social. São Paulo: WMF Martins Fontes, 2012a.

Teoria do agir comunicativo: Volume II - sobre a crítica da razão funcionalista. São Paulo: WMF Martins Fontes, 2012b.

HONNETH, Axel. Teoria Crítica. In: GIDDENS Anthony; TURNER Jonathan (org). Teoria Social Hoje. São Paulo: Unesp, 1999.

Luta por reconhecimento: a gramática moral dos conflitos sociais. São Paulo: Editora 34, 2003a.

Redistribution as Recognition. In: FRASER, Nancy; HONNETH, Axel.

Recognition or Redistribution? Londres: Verso, 2003b.

JOAS, Hans. The Unhappy Marriage of Hermeneutics and Functionalism. In:

HONNETH, Axel; JOAS, Hans (eds.) Communicative Action: Essays, on Jürgen Habermas's the theory of communicative action. Cambridge MA: The MIT Press, 1991. 
; KNOBLE, W. Social Theory: Twenty Introductory Lectures. Cambridge: Polity Press, 2009.

LUBENOW, Jorge Adriano. As críticas de Axel Honneth e Nancy Fraser à filosofia polítca de Jürgen Habermas. Veritas. Porto Alegre, v. 55, n. 1 jn/abr. 2010, p. 121-134.

LUKÁCS, Georg. História e consciênci de classe: estudos sobre a dialética marxista. São Paulo: WMF Martins Fontes, 2012.

Para um ontologia do ser social I. São Paulo: Boitempo, 2015.

MÉSZÁROS, István. O conceito de dialética em Lukács. São Paulo: Boitempo, 2013.

MULGAN, Tim. Utilitarismo. Petrópolis, RJ: Vozes, 2012.

VANDERNBERGHE, Frédéric. Prefácio à edição brasileira: metateoria, teoria social, teoria sociológica. In: Uma história filosófica da sociologia alemã: Alienação e

reificação. Volume I: Marx, Simmel, Weber e Luckács. São Paulo: Annablume, 2012.

A sociologia como uma filosofia prática e moral (e vice e versa). Sociologias. Porto Alegre: Ano 17, no 39, Mai/ago 2015, p. 60-109.

Recebido em 11-05-2017;

Revisado em 19-10-2018;

Publicação em 15-12-2018. 